Revista de

Contabilidade e

Organizações

\title{
UMA ANÁLISE DA SEPARAÇÃO ENTRE A PROPRIEDADE E A GESTÃO NASCOOPERATIVAS DE CRÉDITO BRASILEIRAS
}

\section{AN ANALYSIS OF THE SEPARATION OF PROPERTY AND MANAGEMENT IN BRAZILIAN CREDIT UNIONS}

\author{
Luana Zanetti Trindade ${ }^{a}$; Sigismundo Bialoskorski Neto ${ }^{b}$ \\ a Mestranda em Controladoria e Contabilidade pela Faculdade de Economia, \\ Administração e Ciências Contábeis de Ribeirão Preto-USP. \\ E-mail:luanazanetti@hotmail.com \\ ${ }^{b}$ Pós doutorado na Universidade do Missouri EUA e Universidade Giessen Alemanha \\ Docente da Faculdade de Economia, Administração e Contabilidade de Ribeirão Preto - USP \\ E-mail:sig@usp.br
}

\section{Resumo}

Esse trabalho tem como objetivo analisar se as principais práticas de governança corporativa em cooperativas de crédito tem correlação com variáveis que caracterizam tamanho e escala financeira das cooperativas e em particular a variável de divisão entre a propriedade e a gestão. Para tanto, se utilizou dos dados do projeto de Boas Práticas de Governança Corporativa do Banco Central, Bacen (2009) e em função do grande número de variáveis, elaborou-se uma análise estatística multivariada fatorial pelos componentes principais. Os resultados, após a extração de 3 fatores, mostram que a separação entre a propriedade e a gestão se correlaciona negativamente com as variáveis de governança características da gestão tradicional em cooperativas- e de forma positiva com as outras variáveis que representam as melhores práticas indicadas de governança. Mas, não apresentam correlação com tamanho econômico e financeiro, o que implica em uma nova questão de pesquisa, se a divisão entre propriedade e gestão é importante para a eficiência dos negócios das cooperativas de crédito brasileiras ou se essas apresentam como organizações sociais uma diferente lógica de governança corporativa também eficiente.

Palavras-chave: Governança corporativa; Cooperativas de crédito; Direito de propriedade; Controle.

\section{Abstract}

This study aims to analyze how the main corporate governance practices in cooperatives is correlated with variables characterizing size and scale of financial cooperatives and in particular the variable division between ownership and management. For this purpose, we used data from the Corporate Governance Project of the Central Bank, Bacen (2009) and due to the large number of variables, was conducted a factorial multivariate analysis by principal components. The results, after the extraction of three factors show that the separation of ownership and management is negatively correlated with the variables of governance characteristics of traditional management in cooperatives, and positively with other variables that represent the best practices set of governance. But doesn't presents correlate with economic and financial size, which implies a new research question, if the division between ownership and management is important for the business efficiency of the Brazilian credit cooperatives or social organizations like these have a different logic corporate governance also efficient.

Keywords: Corporate governance, Credit union, Separating ownership and Management. 


\section{INTRODUÇÃO}

De acordo com Hansmann (1996), os proprietários de uma firma são as pessoas que dividem duas formas de direito formal: o direito de controle da firma e o direito de apropriação dos lucros ou direitos residuais desta. Quando o número de proprietários é grande é necessária a separação entre a propriedade e a gestão. A separação entre a propriedade e a gestão implica na necessidade da formulação de contratos para delimitação das responsabilidades, para evitar o oportunismo e diminuir a racionalidade limitada das partes, e em custos de transação para elaboração e cumprimento desses contratos.

Devido ao fato dos contratos serem incompletos, sendo impossível a elaboração de um contrato que previna todas as possibilidades de futuras ocorrências, para manter o alinhamento de interesse das partes reduzindo os conflitos de agência fazem-se necessárias estruturas de governança corporativa para coordenar e monitorar essas atividades.

Nas cooperativas de crédito as práticas de governança corporativa provêm em grande parte, das normas estabelecidas por órgãos como Plano Contábil das Instituições do Sistema Financeiro Nacional (COSIF) das determinações contidas nos manuais do BACEN, que instituem as determinações que vão desde regulamentação e padronização contábil para facilitar a fiscalização até a qualificação de seus executivos e gestão para administração.

Para assegurar uma eficaz governança nas instituições financeiras é necessário o esforço de construir um sistema de sólidos controles internos que sustente a estabilidade e a continuidade das atividades individuais, e por consequência à própria estabilidade sistêmica do Sistema Financeiro Nacional (VENTURA, 2009).

Assim, alguns aspectos de governança corporativa em cooperativas de crédito são importantes, como a profissionalização da gestão e a divisão entre a propriedade e a gestão da organização. O Banco Central do Brasil preocupado com essas questões indica a necessidade de se adotar essas entre as melhores práticas. Por outro lado isso implica em prováveis maiores custos de governança, e assim pequenas cooperativas de recursos limitados poderiam ter problemas de eficiência. Desta forma coloca-se a seguinte questão de pesquisa, se essas práticas indicadas pelo Banco Central para a adoção, em particular a separação entre a propriedade e a gestão, tem correlação com outras características de práticas de governança, e bem como com aquelas que caracterizam tamanho e escala econômica da cooperativa.

Desta forma, o objetivo desse trabalho é analisar as correlações existentes entre práticas de governança corporativas em cooperativas de crédito, e seu tamanho econômico e social. Para tanto, esse trabalho descreve a teoria sobre direito de propriedade, agenciamento e custos de transação em cooperativas. Após, se utiliza de dados do projeto de Governança Corporativa do Banco Central, Bacen (2009), selecionando variáveis que indicam tamanho econômico e social, monitoramento, e governança em cooperativas para com essa variáveis selecionadas elaborar análises multivariadas, análise fatorial pelos componentes principais, para ao final apresentar considerações e conclusões.

\section{REFERENCIAL TEÓRICO}

\subsection{A separação do Direito de Propriedade do Controle}

Os proprietários de uma firma são as pessoas que dividem duas formas de direito formal: 
o direito de controle da firma e o direito de apropriação dos lucros ou direitos residuais desta. Em teoria, o direito de controle e o direito ao lucro residual podem ser separados e realizados por diferentes classes de pessoas. Na prática eles são geralmente realizados de forma conjunta. Isso ocorre porque se aquele que detém o controle não tiver qualquer direito sobre os direitos residuais, apresentará pouco interesse de sua parte em usar seu controle para maximizar os ganhos da organização (HANSMANN, 1996).

Como afirmam Hart e Moore (1998) na Teoria do Direito de Propriedade, os proprietários além de deter o direito aos resíduos, também tem o direito de tomar todas as decisões sobre os ativos da firma que não foram especificados em contratos de forma ex ante a contratação. Isso ocorre devido à impossibilidade de completude dos contratos em função dos custos de contratação.

Em uma cooperativa os associados membros são os proprietários, os gestores da organização e ao mesmo tempo aqueles que têm direito aos resíduos, os resultados.

Com o desenvolvimento das organizações, a abertura de capital e a pulverização do controle em um número grande de acionistas, tende a desenvolver uma divisão das funções antes atribuídas a propriedade. Dessa forma, se reconhece o controle como algo independente da propriedade (BERLE; MEANS, 1987). A separação entre as funções é comum em organizações com grandes parcerias profissionais e em entidades sem fins lucrativos, como as cooperativas (FAMA; JENSEN, 1983).

Berle e Means (1987) afirmam que os agentes que exercem o controle sobre as organizações podem não ter direitos de propriedade sobre o resíduo gerado, ou seja, podem não ser proprietários. Assim, o problema que surge pode ser caracterizado como o da relação entre agente e principal (conflito de agência), sendo necessário desenhar contratos ou desenvolver estruturas eficientes que monitorem e motivem os agentes (gerentes) a atuar de forma alinhada aos interesses do principal (proprietário).

Esse problema é decorrente da separação entre a propriedade e a gestão (IBGC, 2012). Esse é um dos principais problemas nas cooperativas por terem propriedade difusa com múltiplos principais.

Assim, é necessário distinguir as organizações cooperativas das organizações privadas com relação ao exercício do controle. A propriedade de uma cooperativa é diferente da de uma empresa listada em bolsa de valores porque as ações da cooperativa não são normalmente transferíveis tão livremente. Na prática, o benefício e o valor agregado produzido por uma cooperativa reverte para os seus proprietários, que são os associados por meio das relações comerciais entre cooperados e a cooperativa (PELLERVO; 2000).

De acordo com Berle e Means (1987), nas empresas privadas o controle é exercido pelo grupo detentor da maioria dos votos do conselho. O que não acontece nas cooperativas. Definido o grupo majoritário nas empresas, os custos de transação declinarão rapidamente, uma vez que esse grupo terá o direito de escolher os agentes aos quais delegará o controle.

Por outro lado, para Hansmann (1996) e Zylbersztain (1994) o processo gerencial das cooperativas tende a não separar a propriedade do controle, pois geralmente os dirigentes são associados de acordo com a legislação. Ou seja, o associado é proprietário e cliente da própria organização.

Considerando ainda a cooperativa, ela é uma organização em que a propriedade é atribuída ao seu grupo de associados (ZYLBERSZTAIN, 1994). Dessa forma, as decisões são tomadas com base no princípio de que um homem equivale a um voto, independentemente da 
participação do cooperado no capital da cooperativa. Seu direito sobre o resíduo dependerá das transações realizadas com a cooperativa no período, mas seu voto independerá desse valor. Assim, cooperados intensamente envolvidos, e que correm os riscos associados ao desempenho da cooperativa, podem ter o mesmo poder de influência em seu processo de tomada de decisões que outro cooperado apenas eventual participante dos negócios (HANSMANN, 1996).

Entretanto, se não há separação entre propriedade e controle na cooperativa, um número muito grande de indivíduos não pode reunir efetivamente seu capital em uma única organização sem que alguns percam o controle. Dessa forma, não é possível que todos os membros exerçam os principais elementos do controle e a transferência deste para alguns responsáveis pode gerar conflitos de agência. A situação criada pode afetar o desempenho corporativo (BERLE; MEANS, 1987).

Nesse contexto de propriedade pulverizada como é o caso das cooperativas, no qual vários agentes contratuais possuem direito residual ao controle, muitos problemas de governança corporativa advêm do fato dos diversos proprietários desejarem exercer o controle de maneira diferente devido a divergências de interesses (BECHT et al, 2005). Dessa forma, torna-se inviável a tomada de decisões de maneira coletiva e parte do poder de decisão e controle sobre os ativos da organização é delegado à gestores, dando origem a um contexto de separação de propriedade e controle.

Sem essa separação os proprietários residuais têm pouca proteção contra ações oportunistas dos agentes de decisão, e isso diminui o valor irrestrito de reivindicações residuais (FAMA; JENSEN, 1983).

A separação entre a propriedade e a gestão existe se os proprietários são desvinculados das decisões de gestão e é recomendada para as organizações de propriedade difusa e complexas, como as cooperativas (COSTA et al., 2012).

O Bacen indica (VENTURA et al, 2009), não sendo de forma obrigatória para as cooperativas de crédito, que o cargo de diretor presidente e presidente do CA não deva ser ocupado pela mesma pessoa. Nesse mesmo sentido, o código do IBGC (2009) também indica a dualidade de cargos como boa prática de governança para as organizações.

Dessa forma, não haveria concentração de poder na organização reduzindo-se os conflitos de agência. Assim, deve-se garantir que o interesse dos proprietários seja mantido e que os riscos da atividade não sejam alocados aos responsáveis pela decisão de gestão (BAYSINGER, HOSKISSON; 1990).

Compreender a relação entre a separação da propriedade e a gestão é uma questão saliente para uma variedade de stakeholders. Não só impacta tanto os proprietários e gerentes da empresa, mas também é importante para as partes relacionadas e os reguladores (COLE et al., 2011).

Dessa forma, a dualidade de cargos entre presidente da cooperativa e presidente CA favorece essa situação de preservar os interesses dos proprietários. Nos países desenvolvidos como Holanda, EUA, Suécia, Finlândia se estabelece a existência do Conselho de Administração eleito pelos associados para executar as decisões de controle e a contratação de executivos responsáveis pela gestão da cooperativa (COSTA et al., 2012).

Mas a característica mais importante consiste no fato de Conselho de Administração ter direito de controle formal sobre o gestor, que consiste em autoridade para nomear ou demitir na medida em que os contratos entre ambos não sejam cumpridos (COSTA et al, 2012). 
Alchian e Demsetz (1972), Fama e Jensen (1983), Jensen e Meckling (1976), propõem as seguintes condições para que a separação entre propriedade e gestão exista, ou seja, para que os proprietários dos direitos residuais da organização sejam desvinculados das decisões de gestão:

Condição 1: Os proprietários delegam o direito de controle formal ao Conselho de Administração, ou seja, lhes transferem autoridade formal sobre o controle da organização.

Condição 2: As decisões de controle e gestão são alocadas respectivamente no Conselho de Administração e ao agente responsável pela gestão.

Para esses autores a condição 1 é satisfeita se o conselho administrativo tem autoridade para nomear e destituir o agente investido de autoridade para administrar a gestão, mesmo que ele seja um dos seus membros, sem consultar os demais proprietários

Para que a condição 2 seja atendida é necessário que o conselho aloque autoridade sobre as decisões de gestão para o agente definido como o principal responsável pela gestão da organização.

Entretanto, a condição 2 não é atendida se o presidente do Conselho de Administração ou diretor presidente assume ambos os cargos e passa, por esse motivo, a propor e ratificar os projetos de investimento da organização (COSTA et al, 2012). A condição 1 representa a condição necessária para a separação entre propriedade e gestão existir de jure, enquanto a condição 2 determina se a mesma ocorre de facto (COSTA, 2010).

Assim, não há separação entre propriedade e gestão. Dessa forma, as cooperativas que não apresentarem separação entre os cargos de diretor presidente e presidente do CA, não apresentam as boas práticas de governança corporativa indicadas pelo BACEN, umas vez que essa é uma das principais atividades de boa governança indicadas as cooperativas de crédito.

Apesar da separação entre propriedade e gestão não ser uma prática obrigatória e ser apenas indicadas pelo Bacen e IBGC (2009), o Banco Central está estimulando essa atividade porque em breve ela se tornará obrigatória para as cooperativas de crédito brasileiras.

O objetivo dessa atitude é melhorar a gestão da administração. Isso, pois segundo Fama e Jensen (1983), essa divisão das decisões é que explica a sobrevivência das organizações. Isso ocorre, pois a separação entre propriedade e gestão auxilia no controle do problema de agência originado da delegação dos direitos de controle ou autoridade.

Costa (2010), em seu trabalho define as variáveis que caracterizam a alocação dos direitos de propriedade e decisões em organizações cooperativas, são elas: contratar e demitir o responsável pela gestão, ratificar os projetos de investimentos, monitorar o desempenho da gestão, propor projetos e implementar projetos. Assim, esse autor compõe por meio dessas variáveis um índice de separação entre propriedade e controle.

Esse índice proposto por Costa (2010) para averiguação da condição 1 é composto por dois elementos: o primeiro representa como os direitos de controle residual e formal estão alocados na organização. O segundo elemento é refletido na relação de agência entre Conselho de Administração e o responsável pela gestão.

Para averiguação da condição 2 pode-se obter informações sobre o nível de dedicação do presidente do Conselho de Administração às atividades da cooperativa e a existência de dualidade de cargos do diretor presidente e presidente do CA. Assim, por meio desse índice desenvolvido pelo autor é possível identificar o tipo de separação que pode variar entre 
separação de jure ou de facto, separação parcial e inexistente (COSTA, 2010).

Por fim, esse momento de separação entre propriedade e controle representou a substituição da mão invisível do mercado de Adam Smith pela mão invisível da hierarquia da grande empresa. Esse novo modelo exigiu a formação de uma hierarquia gerencial (MCGRRAW; CHANDLER, 1998). Essa situação leva a necessidade da formulação de contratos para delimitação das responsabilidades, para evitar o oportunismo e diminuir a racionalidade limitada das partes e em custos de transação para elaboração e cumprimento desses contratos.

\subsection{Visão contratual da firma e economia de custo de transação}

O conflito de agência citado anteriormente é um elemento essencial da chamada visão contratual da firma desenvolvida entre outros por Coase (1937), Alchiam e Demsetz (1972) e Fama e Jensen (1983). Os contratos se fazem necessários a partir do momento que as transações devem ser delimitadas para evitar o comportamento oportunista das partes e devido à racionalidade limitada existente.

Esses são custos de instalação e implementação associados às estruturas de governança, e os custos incorridos em ambas as partes para garantir ao outro lado o comprometimento efetivo ao acordo.

Os problemas ex post surgem porque nenhum contrato é perfeito e é quase impossível a delimitação de todos os custos ex ante. Associado aos problemas ex post se tem os problemas de agenciamento que geram custos devido a seus conflitos de agência. Esses custos de agência são formados pelos custos de monitoramento do agente pelo principal para garantir que seus interesses sejam atingidos, além dos gastos com seguros e perdas residuais decorrentes das atividades realizadas.

Dessa forma, a origem da governança corporativa está associada à pulverização do controle da empresa norte-americana, e o crescimento do poder dos gestores em relação aos investidores. Assim, a governança nasce como uma reação desses investidores para controlar o destino da empresa, realizando seu controle estratégico e evitando o comportamento oportunista dos agentes.

Williamson (1985) analisou no contexto da Economia dos Custos de Transação que leva em conta os pressupostos de oportunismo e racionalidade limitada que os contratos entre agente e principal apresentam custos associados que devem ser contrapostos aos ganhos potenciais de eficiência, advindos da separação entre propriedade e controle.

A separação entre propriedade e gestão (controle) estabelece o marco inicial dos problemas de governança, pois envolvem questões de alinhamento de interesses entre as partes (agente e principal), desequilíbrio no acesso a informação, propensão a riscos (assimetria de informação) e aspectos formadores da motivação que passaram a diferenciar objetivos dos proprietários e dos gestores (MCGRRAW; CHANDLER, 1998).

Considera-se então que os contratos são incompletos sendo impossível a elaboração de um contrato que previna todas as possibilidades de futuras ocorrências. E, além disso, para manter o alinhamento de interesse das partes reduzindo os conflitos de agência, fazem-se necessárias estruturas de governança corporativa para coordenar e monitorar essas atividades. Nas cooperativas que são organizações com múltiplos principais, esses custos de agenciamento são de fundamental importância. 


\subsection{Definição e conceitos de governança corporativa}

A governança corporativa segundo o Instituto Brasileiro de Governança CorporativaIBGC (2009) é o sistema por meio do qual as organizações são dirigidas, monitoradas e incentivadas, envolvendo o relacionamento entre proprietários.

De acordo com Sheifer e Vishny (1997), a governança corporativa trata das maneiras pelas quais os fornecedores de recursos financeiros às corporações se asseguram que irão obter retorno do que fora investido. É o sistema que as organizações são dirigidas e controladas por normas e princípios, com a preocupação associada ao crescimento e diversificação das empresas, que exige profissionalismo, especialização e complexidade de gestão. De acordo com Ventura (2009) ela tem como objetivo alinhar os sistemas de controle, monitoramento e incentivos para que as decisões dos gestores sejam realizadas no melhor interesse dos proprietários.

Ela vem como resposta a registros de expropriação de riquezas por parte dos gestores, prejudicando assim os proprietários. Esses registros decorrem do problema de agência dos gestores que baseiam suas atitudes no objetivo de maximizar sua utilidade pessoal e não na riqueza dos acionistas, objetivo pelo qual foram contratados.

Para Bechtet al (2005) o problema de governança corporativa também pode ser descrito como um problema de agência comum, envolvendo agente e múltiplos principais. As suas regras podem ser vistas como resultado do processo de contratualização entre esses vários principais e o agente (gestor).

Para controlar os problemas causados pela separação entre propriedade e controle é necessária uma abordagem que reduza esses problemas de agência. Pois a estrutura de contratos das organizações separam a homologação e o monitoramento das decisões de iniciação e implementação das decisões (FAMA; JENSEN, 1983).

Assim, entende-se a governança corporativa como o sistema por meio do qual se exerce e se monitora o controle nas corporações. $\mathrm{O}$ enfoque predominante dessa questão, na literatura econômica é o da Teoria da Agência.

Essa teoria afirma que os agentes são racionais e avessos a risco. Ela é composta por duas partes, o agente e o principal. O agente fica responsável pelas decisões e com o controle que afetam os retornos do principal. Ou seja, o bem estar do principal depende das decisões do agente. Os conflitos de agência ocorrem porque ambas as partes querem maximizar seus interesses que podem ser distintos (JENSEN; MECKLING, 1976).

Dada essa situação de conflito, existem os custo de agência que podem ser definido como custo de monitorar e gerenciar o oportunismo que a organização irá incorrer até mesmo se os interesses de todos forem iguais (HANSMANN, 1988).

De acordo com Jensen e Meckling (1976) os custos de agência são a soma dos:

1. Custos de criação e estruturação de contratos entre principal e agente;

2. Custos de monitoramento das atividades dos gestores pelo principal;

3. Custos promovidos pelo próprio agente para mostrar ao principal que seus atos não o irão prejudicar;

4. Perdas residuais decorrentes da diminuição da riqueza do principal por divergências entre as decisões do agente e as decisões que iriam maximizar a riqueza do principal. 
$\mathrm{Na}$ relação entre acionistas e gestores, os acionistas podem monitorar as atividades dos gestores para diminuição desse conflito através de limitações contratuais. Muito se têm discutido sobre a importância dos modelos de governança corporativa como um diferencial na administração dos negócios das empresas, e também sobre os reflexos da estrutura de desempenho da organização (CVM, IBGC, BACEN). As práticas dos códigos de governança corporativa poderiam promover maior qualidade ao desenvolvimento de suas atividades.

No caso das cooperativas esse monitoramento é importante e não há organização que cumpra um papel institucional de regulação como há a Comissão de valores Mobiliários CVM para as empresas de capital aberto. Assim as cooperativas são organizações de múltiplos principais que não contam com um regulamento específico. Mas cooperativas de crédito tem um monitoramento exercido pelo BACEN.

O pressuposto básico sobre governança é que os obstáculos relacionados a um ambiente de falta de governança se constituem em entraves à eficiência e ao desenvolvimento das organizações, em relação à realização de seus objetivos de funcionamento, em última instância, relativos ao atendimento dos anseios das partes interessadas da organização (SIVEIRA, 2004).

Segundo Silveira (2004) a grande maioria dos estudos assumem que os mecanismos de governança são variáveis independentes, isto é variáveis exógenas que não possuem relação com os demais mecanismos de governança corporativa ou com outras características da empresa. É possível, entretanto que alguns mecanismos de governança, ou a própria qualidade da governança corporativa, sejam variáveis endógenas, ou seja, variáveis influenciadas por outros mecanismos de governança ou por outras variáveis corporativas.

Entre os aspectos endógenos citados por Klapper e Love (2002) três aspectos se destacam como determinantes de governança corporativa: a utilidade da governança corporativa, a natureza das operações e o tamanho da companhia. Em primeiro lugar, é de se esperar que empresas com maior oportunidade futura de crescimento, percebam uma maior utilidade na adoção de melhores práticas de governança do que empresas sem grandes expectativas de captação futura de recursos.

Segundo, na natureza das operações, a expropriação da riqueza do acionista minoritário é mais fácil para algumas empresas, pois empresas com grandes proporções de ativos intangíveis devido a sua dificuldade de mensuração, teriam maior facilidade de expropriação do que empresas com ativos fixos.

O terceiro fator se relaciona ao tamanho da empresa, que segundo Klapper e Love (2002) influencia a governança corporativa de maneira de duas formas opostas. As empresas maiores podem apresentar maiores problemas de agência decorrentes de seu fluxo de caixa livre, levando a uma necessidade de melhores práticas de governança para compensar esse problema. Além disso, as empresas maiores em geral dispõe de mais recursos para implementar práticas recomendadas de governança.

Por outro lado, empresas menores tem a tendência a crescerem mais e a necessitarem de capital externo. Dessa forma, tanto a empresa pequena quando a grande possuem incentivos para adotar melhores práticas de governança corporativa.

Entre os aspectos endógenos citados por Hilmmelberg et al(1999) os custos de agência e monitoramento poderiam ser maiores nas empresas grandes aumentando a necessidade de maior concentração da estrutura de propriedade. Por outro lado, as grandes empresas poderiam usar a economias de escalas no monitoramento da alta gestão utilizando, por exemplo, agência de rating o que levaria a um menor nível ótimo de concentração da propriedade. 
No Brasil, as discussões sobre governança são relativamente novas. O código de governança e a criação do Instituto Brasileiro de Governança Corporativa IBGC iniciaramse na década de 90 . Já a criação de um código de governança corporativa para cooperativas no Brasil é mais recente e somente em 2006 que a Organização das Cooperativas do Brasil sistematizou um documento nessa área (BIALOSKORSKI NETO; DAVIS, 2010). Os problemas de agenciamento em cooperativas, bem como, o monitoramento decorrente desses, em uma situação em que a cooperativa é caracterizada por uma organização de múltiplos principais, causam custos, que podem ser significativos nas pequenas cooperativas.

\subsection{Importância econômica das cooperativas de crédito}

As cooperativas de crédito são instituições financeiras constituídas sob a forma de sociedade cooperativa, que tem como objeto a prestação de serviços financeiros aos associados, como concessão de crédito, captação de depósitos à vista e a prazo, cheques, prestação de serviços de cobrança, de custódia, de recebimentos e pagamentos por conta de terceiros sob convênio com instituições financeiras públicas e privadas e de correspondente no País, além de outras operações específicas e atribuições estabelecidas na legislação em vigor (PINHEIRO, 2008).

Uma cooperativa de crédito está apta a realizar praticamente as mesmas operações financeiras permitidas a um banco comercial. Além de receberem depósitos a vista, realizam operações ativas de concessão de créditos em diversas modalidades, mostrando que incorrem nos mesmos riscos de intermediação financeira que ocorrem com os bancos múltiplos e comerciais em geral.

As cooperativas de crédito segundo a Organização das Cooperativas BrasileirasOCB (2011) são cooperativas designadas a promover a poupança e financiar necessidades ou empreendimentos dos seus cooperados. Ela disponibiliza crédito rural e urbano. As operações de crédito no Brasil, das cooperativas de crédito chegam a $\mathrm{R} \$ 29,8$ bilhões de reais. O número de cooperativas é de 1.370 .

O cooperativismo de crédito é um dos ramos mais fortes em países como França, Estados Unidos, Japão, Espanha, Alemanha e Canadá. Segundo Pinheiro (2008) as cooperativas de crédito são um importante instrumento de desenvolvimento em muitos países. Na Alemanha, as cooperativas de crédito possuem cerca de quinze milhões de associados. Na Holanda, o banco cooperativo Rabobank atende a mais de $90 \%$ das demandas financeiras rurais. Nos Estados Unidos, há mais de doze mil unidades de atendimento cooperativo apenas no sistema CUNA (Credit Union Nacional Association).

Nos Estados Unidos, os bancos cooperativos agrícolas respondem por mais de um terço dos financiamentos agropecuários norte-americanos. De acordo com dados da Agência de Estatística da União Européia de 2000, 46\% do total das instituições de crédito da Europa eram cooperativas, com participação de 15\% da intermediação financeira (PINHEIRO, 2008).

De acordo com esse mesmo autor, em alguns países, como Irlanda e Canadá, o cooperativismo de crédito ocupa, com bastante eficiência, espaços deixados pelas instituições bancárias, como resposta ao fenômeno mundial da concentração, reflexo da forte rivalidade no setor financeiro. Dessa forma, as cooperativas conseguem ofertar serviços mais adequados às necessidades locais. 
Esses números dos países demonstram o potencial de crescimento do cooperativismo de crédito no Brasil, segmento considerado ainda extremamente modesto se comparado ao de países mais desenvolvidos.

No Brasil as cooperativas de crédito estão presentes desde o inicio do século XX. Após a constituição de 1988, o cooperativismo de crédito inicia a sua reorganização e há nos anos 90 a criação de dois Bancos, o Bancoob que pertence a 14 cooperativas centrais de crédito e o Brasicredi, o que possibilitou uma trajetória de crescimento dos sistemas de crédito cooperativo no Brasil.

A consolidação do ramo crédito ocorre após a abertura dos bancos cooperativos durante a década de 90, o que também contribui para a evolução da organização do setor e permite o oferecimento dos serviços bancários maios completos aos associados. Entretanto, mesmo dada tal evolução, esse abrange aproximadamente somente $3 \%$ da população brasileira e participa de apenas $1,7 \%$ do sistema financeiro Brasileiro. O cooperativismo de crédito tem dificuldades para aumentar a fatia de mercado em relação ao conjunto das instituições financeiras e cresceu menos de que poderia ter crescido nos últimos anos quando comparado com o conjunto das instituições financeiras (TRINDADE et al, 2010).

\subsection{Práticas de governança corporativa para cooperativas de crédito}

Em relação às práticas de governança corporativa em instituições financeiras elas provêm em grande parte, das normas estabelecidas por órgãos como Plano Contábil das Instituições do Sistema Financeiro Nacional (COSIF) das determinações contidas nos manuais do BACEN, que instituem as determinações que vão desde regulamentação e padronização contábil para facilitar a fiscalização até a qualificação de seus executivos e gestão para administração.

As diretrizes adotadas pelo Banco Central vão além do simples relacionamento da instituição com partes interessadas externas ou da preocupação com seus demonstrativos contábeis, pois considera todos os aspectos relacionados à gestão da instituição e também, especificamente, ao seu sistema de controles internos.

Para assegurar uma eficaz governança nas instituições financeiras é necessário o esforço de construir um sistema de sólidos controles internos que sustente a estabilidade e a continuidade das atividades individuais, e por consequência a própria estabilidade sistêmica do Sistema Financeiro Nacional (VENTURA, 2009).

Por determinação da lei 5.764/71 um associado não pode deter mais do que um terço do capital. Ou seja, o associado que detiver maior participação no capital não tem qualquer benefício superior em relação aos demais. Esse fator é determinante para que não haja concentração, mas sim pulverização da participação no capital, ambiente esse propício para desenvolvimento dos conflitos de agência (PINTO et al, 2009).

Mas o cooperado sendo ao mesmo tempo agente e principal tem seus objetivos particulares no lugar da eficiência da cooperativa, ou seja, uma relação de oportunismo contratual. O cooperado (o principal) pode ter menos informação sobre o comportamento do gestor (agente) que o próprio gestor, o que o leva a ter atitudes conforme seus interesses pessoais, mesmo sendo contrastantes ao interesse do cooperado. Para esse problema, um sistema de incentivo ao cooperado poderia reduzir esse tipo de ação e aumentaria a eficiência da cooperativa (BIALOSKORSKI NETO, 2005). 
Existem problemas inerentes a atividade da cooperativa como o princípio da democracia que é exercício pela tomada de decisão em assembleia geral e reuniões dos Conselhos que geram altos custos transacionais. Além disso, o fato de um membro representar um voto implica diretamente em altos custos de agência. E a distribuição proporcional das sobras de acordo com operações não permite a percepção do membro como investidor gerando custos transacionais (BIALOSKORSKI NETO; BARROSO; REZENDE, 2010).

Essas são características das organizações cooperativas e refletem a necessidade de melhores parâmetros de governança corporativa para melhorar a eficiência econômica e para incentivar a profissionalização do órgão executivo de gestão dentre outras.

Assim, com o intuito de melhorar a eficiência das cooperativas de crédito, o Banco Central do Brasil diagnosticou por meio de estudos e pesquisas as características da governança das cooperativas de crédito e definiu uma série de boas práticas recomendadas para dessa forma, disseminar e incentivar a adoção dessas práticas pelas cooperativas de crédito (VENTURA, 2009).

As boas práticas de governança corporativa ao disciplinar os processos de decisão coletiva dão mais clareza aos objetivos e a política da cooperativa, contribuindo para promover a atuação eficiente dos gestores, mobilização dos empregados e maior confiança para os associados. A boa governança certamente está fundamentada em bom fluxo de informações e na necessidade de obtenção de informação de qualidade de maneira pontual e acessível. Além disso, a difusão das boas práticas de governança pode melhorar todo o ambiente de negócio, uma vez que contribui para diminuição de problemas de assimetria de informação e direitos entre associados e gestores.

As práticas de governança corporativa podem ser indicadas ou obrigatórias. As práticas indicadas são aquelas que não têm adesão forçada ou normatizada por um órgão competente, como por exemplo, as melhores práticas do manual do IBGC (2009) indicadas para várias organizações. E um outro exemplo seriam as melhores práticas de governança do Bacen para cooperativas de crédito.

Mas as práticas obrigatórias de governança devem ser seguidas, pois são impostas e normatizadas pelos respectivos órgãos competentes. Por exemplo, as práticas de governança normatizadas pelo Bacen para as cooperativas de crédito e demais instituições financeiras. Outro exemplo obrigatório são as práticas de governança específicas para cada nível das empresas negociadas na bolsa de valores.

Entre as principais práticas indicadas pelo Instituto Brasileiro de Governança Corporativa também existe entre elas a separação entre a propriedade e gestão. De acordo com a seção 2.10 do Código das melhores práticas de governança corporativa (IBGC, 2009), deve-se ser evitado o acúmulo das funções de presidente do Conselho de Administração e diretor-presidente pela mesma pessoa.

Esse manual também indica a prática de maior transparência, ou seja, a organização deve garantir que sejam prestadas aos stakeholders as informações de seu interesse, além das que são obrigatórias por lei ou regulamento, tão logo estejam disponíveis. Essa comunicação deve ser feita com clareza e prevalecendo a substância sobre a forma de acordo com a seção 3.4 (IBGC, 2009).

Esse manual do IGBC (2009), na seção 4.1 indica a existência de auditoria independente na organização. Assim, as demonstrações financeiras devem ser auditadas por auditor externo independente. O objetivo é verificar se as demonstrações financeiras refletem adequadamente a 
realidade da sociedade.

Já as principais indicações de boas práticas de governança corporativa do Bacen, apresenta como semelhança ao IGBC (2009), a separação da propriedade e a gestão. A seção 2, item 1 das diretrizes de boas práticas de governança em cooperativas de crédito (VENTURA et al, 2009) afirma que deve haver clara separação entre os papéis desempenhados pelos administradores com funções estratégicas (CA ou diretoria) e por aqueles com funções executivas (diretoria executiva ou gerência).

Assim, como o IBGC (2009) o Bacen também indica a transparência como boa práticas de governança. Segundo Ventura et al. (2009) as seções 8 e 9 discorrem sobre a questão de assegurar aos membros dos órgãos de administração estratégica e fiscal as informações das cooperativas. Da mesma forma, assegurar que os cooperados tenham conhecimento e acesso as informações financeiras, estratégicas e de desempenho da cooperativa. Além disso, a comunicação deve ser clara e adequada.

Essas práticas atualmente ainda são indicadas, ou seja, ainda não são de adesão obrigatórias pelas organizações. Mas a principal delas que é a separação entre a propriedade e a gestão será em breve normatizada pelo BACEN.

Quando as práticas de governança como profissionalização da gestão, na separação entre a propriedade e a gestão, e na melhora do monitoramento, implementando ações como de auditoria interna e externa, a melhor atuação do Conselho Fiscal dentre outras, pode significar um novo padrão de custos para as cooperativas. Esse novo padrão de custos de adesão as práticas de governança pode ser incompatível com cooperativas de pequeno tamanho econômico, mas não significativos e imperceptíveis para grandes cooperativas.

Assim, os custos seriam uma variável importante para as pequenas cooperativas, mas não para as grandes. Desta forma espera-se que as grandes cooperativas tenham a adoção de melhores práticas de governança, monitoramento mais intenso, profissionalização e separação entre propriedade e gestão, e que as menores cooperativas, em função do custo dessas práticas não tenham significativo esforço de profissionalização e de monitoramento, bem como estruturas de governança corporativa que impliquem em custos adicionais e perda de eficiência no curto prazo.

\section{METODOLOGIA E RESULTADOS}

O presente estudo é uma pesquisa exploratória e descritiva, pois exploratório é quando o objetivo é analisar um tema ou um problema de pesquisa pouco estudado. Já os estudos descritivos são utilizados quando se deseja descrever as propriedades e características de um fenômeno (SAMPIERI et al., 2006).

Utilizou-se para a pesquisa a base de dados fornecida pelo Banco Central do Brasil que é formado pelas cooperativas de crédito que participaram do projeto de Boas Práticas de Governança Corporativa do ano de 2008. A base de dados é composta por 1.198 cooperativas de crédito e foi utilizada com o objetivo de analisar se a divisão entre a propriedade e a gestão da organização tem correlação com outras variáveis que caracterizam tamanho e escala financeira da cooperativa e outras características de práticas de governança. Foi feita uma análise fatorial com uso do software Statistical Package for the Social Sciences (SPSS) versão 17.

Do total de variáveis presentes no banco de dados do BACEN foram escolhidas as variáveis que pudessem mostrar o tamanho social da cooperativa como número de cooperados, também aquelas que pudesse mostrar o tamanho financeiro da cooperativa como receitas, 
despesas administrativas, sobras e ativo.

Para identificar o conjunto de práticas de governança corporativa, foram escolhidas as que indicassem o monitoramento, como a de presença de auditoria interna, a obrigatoriedade dos diretores em prestar contas, as que demonstram a preocupação com a especialização do Conselho Fiscal, e independência na eleição do Conselho de Administração e o Conselho Fiscal.

Quanto às práticas de governança que representam a relação entre cooperados e a cooperativa, foram escolhidas a presença de educação cooperativa, e as formas de realização da assembleia geral por delegação. Para aferir a separação entre propriedade e gestão escolheu-se a variável que apresenta se o cargo de diretor presidente da cooperativa e presidente do Conselho de Administração é ocupado pela mesma pessoa.

Segundo Costa (2010), há um conjunto de condições necessárias para se estabelecer a separação entre a propriedade e a gestão. Considerou-se neste trabalho a condição de as decisões de controle e gestão serem alocadas respectivamente no Conselho de Administração e ao agente responsável pela gestão, sendo usada como proxy de separação entre propriedade e gestão sendo representada pela dualidade de cargos. Ou seja, o fato do cargo de diretor presidente não ser ocupado pela mesma pessoa que ocupa o cargo de presidente do CA.

Caso o presidente do Conselho de Administração ou diretor presidente assuma ambos os cargos e passa, por esse motivo, a propor e ratificar os projetos de investimento da organização, não há separação entre propriedade e gestão. Pois a condição 2 necessária não é satisfeita.

Dessa forma, as cooperativas que não apresentarem separação entre os cargos de diretor presidente e presidente do $\mathrm{CA}$, não apresentam as boas práticas de governança corporativa indicada pelo BACEN.

\subsection{Análise da separação entre propriedade e gestão}

Foi realizada uma análise fatorial pelos componentes principais, em função do grande número de variáveis, para que as correlações entre essas pudessem ser analisadas e entendidas.

Os resultados encontrados, cargas fatoriais apresentadas na figura 1, mostram que após a extração de 3 fatores, o primeiro fator agregou as variáveis de tamanho econômico como o número de associados, receitas, sobras, despesas administrativas, ativo e presença de auditoria interna. O que se faz lógico, uma vez que essas variáveis se expressam em correlação, isto é, quanto maior o número de cooperados possivelmente maior são as receitas, as sobras, as despesas da cooperativa, o ativo e assim se essas são organizações maiores há a necessidade da presença de auditorias e maior controle interno.

O segundo fator se caracteriza pela correlação entre as variáveis de educação cooperativa, presença de comitês eleitorais, treinamento do Conselho Fiscal, obrigatoriedade da prestação de contas dos diretores, e positivamente com a não separação entre as funções de presidente da cooperativa e do conselho administrativo. Esse fator mostra correlações entre características das cooperativas de crédito com uma gestão tradicional, isso é, não há divisão entre a propriedade e a gestão, e isso se correlaciona com práticas inerentes a essas instituições como educação cooperativas, um Conselho Fiscal formado por associados que necessitam treinamento e especialização, e a necessidade de controle com a instituição e a preocupação com a prestação de contas pelos associados/diretores.

O último e terceiro fator foi composto pelas variáveis: permissão de inclusão pelos associados de pautas específicas nas assembleias, pré-requisitos de capacitação técnica para 
se candidatar ao Conselho Fiscal, chapas de Conselho Fiscal e Conselho de Administração independentes, com separação clara de funções, a Assembleia Geral Ordinária - AGO ocorre por regime de delegados eleitos em Assembleias prévias e a variável que representa que o cargo de presidente da cooperativa e do Conselho de Administração são ocupados por pessoas diferentes.

Esse fator mostra a correlações entre variáveis que representam na cooperativa uma preocupação em sua estrutura de governança com a profissionalização e a separação de funções entre membros proprietários e os dirigentes contratados. Deve-se notar a exigência de preparo anterior para se poder candidatar ao Conselho Fiscal e a independência na sua eleição, o que pode garantir um melhor e mais eficaz monitoramento, bem como a divisão entre a propriedade e a gestão.

Do conjunto de variáveis escolhidas, as variáveis de monitoramento foram agrupadas em diferentes fatores, parte como a auditoria interna no fator 1, parte como treinamento do conselho fiscal e a obrigatoriedade de prestação de contas pelos dirigentes no fator 2, por fim parte no fator 3 , não é constituindo em um conjunto de variáveis que pudessem se auto correlacionar em um único fator. Isso indica que a prática de monitoramento, de várias formas, é uma variável que se correlaciona - dependendo da sua forma - com outras características.

Tabela 1: Cargas fatoriais dos 3 fatores extraídos em análise multivariadas pelos componentes principais, com variáveis escolhidas do banco de dados de governança corporativa em cooperativas do BACEN, em 2008

\begin{tabular}{|c|c|c|c|}
\hline \multirow[t]{2}{*}{ Perguntas } & \multicolumn{3}{|c|}{ Componentes } \\
\hline & 1 & 2 & 3 \\
\hline Número de associados & 0.807 & -0.036 & 0.044 \\
\hline Valor da receita & 0.939 & 0.035 & -0.043 \\
\hline Valor das sobras & 0.686 & 0.070 & -0.062 \\
\hline Valor das despesas administrativas & -0.894 & -0.039 & 0.053 \\
\hline Valor do ativo & 0.783 & 0.094 & -0.001 \\
\hline Existência de estrutura própria de auditoria interna & 0.391 & 0.173 & 0.146 \\
\hline A cooperativa promove programa de educação cooperativista & 0.074 & 0.563 & 0.071 \\
\hline $\begin{array}{l}\text { Existência de comitê eleitoral formalizado e independente para conduzir processos } \\
\text { eletivos }\end{array}$ & 0.007 & 0.532 & 0.024 \\
\hline A cooperativa oferece treinamento específico para os membros do Conselho Fiscal & 0.112 & 0.641 & 0.049 \\
\hline $\begin{array}{l}\text { Os diretores executivos prestam contas formalmente de suas atividades ao } \\
\text { Conselho de Administração }\end{array}$ & 0.074 & 0.585 & 0.124 \\
\hline $\begin{array}{l}\text { Os cargos de diretor-presidente e presidente do Conselho de Administração são } \\
\text { ocupados pela mesma pessoa }\end{array}$ & 0.032 & 0.410 & -0.430 \\
\hline $\begin{array}{l}\text { Existência de mecanismos que permitam que cooperados incluam pautas em } \\
\text { assembleia previamente }\end{array}$ & -0.072 & 0.336 & 0.491 \\
\hline Existência de pré-requisitos de capacitação técnica para ser Conselheiro Fiscal & 0.073 & 0.221 & 0.571 \\
\hline Chapas de Conselho Fiscal e Conselho de Administração independentes & 0.018 & 0.141 & 0.496 \\
\hline Assembleia Geral Ordinária ocorre por regime de representação por delegados & -0.015 & -0.242 & 0.539 \\
\hline
\end{tabular}

É possível notar que o fator 1 representou o tamanho econômico da cooperativa, o fator 2 as práticas de participação comum nas cooperativas tradicionais, e o terceiro fator agrupou as práticas mais indicadas pelos códigos de governança corporativa do Bacen.

Em continuidade, se procedeu a uma análise considerando cada uma das cooperativas de acordo com a sua carga fatorial para cada um dos fatores de forma a ser percebido o grau de 
interação entre os fatores, e se analisar os clusters de cooperativas.

Ao fazer uma intersecção das cargas fatoriais entre o fator 1 e 2, nota-se que se tem em cada quadrante uma situação particular, como o exemplo no quadrante 1 as cooperativas com alta carga fatorial no fator 1 , maiores cooperativas, e baixa carga fatorial para o fator 2 , práticas tradicionais de gestão menos intensas, e assim sucessivamente para os outros quadrantes.

Os resultados esperados dessa intersecção seriam que as cooperativas que tivesses maior carga do fator 1 teriam menor carga do fator 2, ou menor carga do fator 1 e maior carga do fator 2, uma vez que as cooperativas tradicionais sem separação entre propriedade e gestão não apresentariam elevado tamanho econômico e escala. Isso poderia ser notado se houvesse concentração das cooperativas na elipse em vermelho do gráfico 1.

Entretanto, o resultado encontrado foi contrário onde a maioria das cooperativas apresentaram uma menor carga fatorial para o fator 1, ou seja, um menor nível de tamanho econômico e escala, associado com maiores cargas fatoriais do fator 2 , ou seja, práticas de participação em cooperativas com governança tradicional. Mas a presença de maior carga fatorial do fator de 1 não implica na menor carga fatorial de 2. Desta forma, pode-se verificar que as práticas tradicionais de governança corporativa em cooperativas bem como a não separação entre gestão e propriedade estão associados, de forma mais intensa, com um menor tamanho econômico e social das cooperativas.

É possível notar isso no gráfico 1 que apresenta essa intersecção.
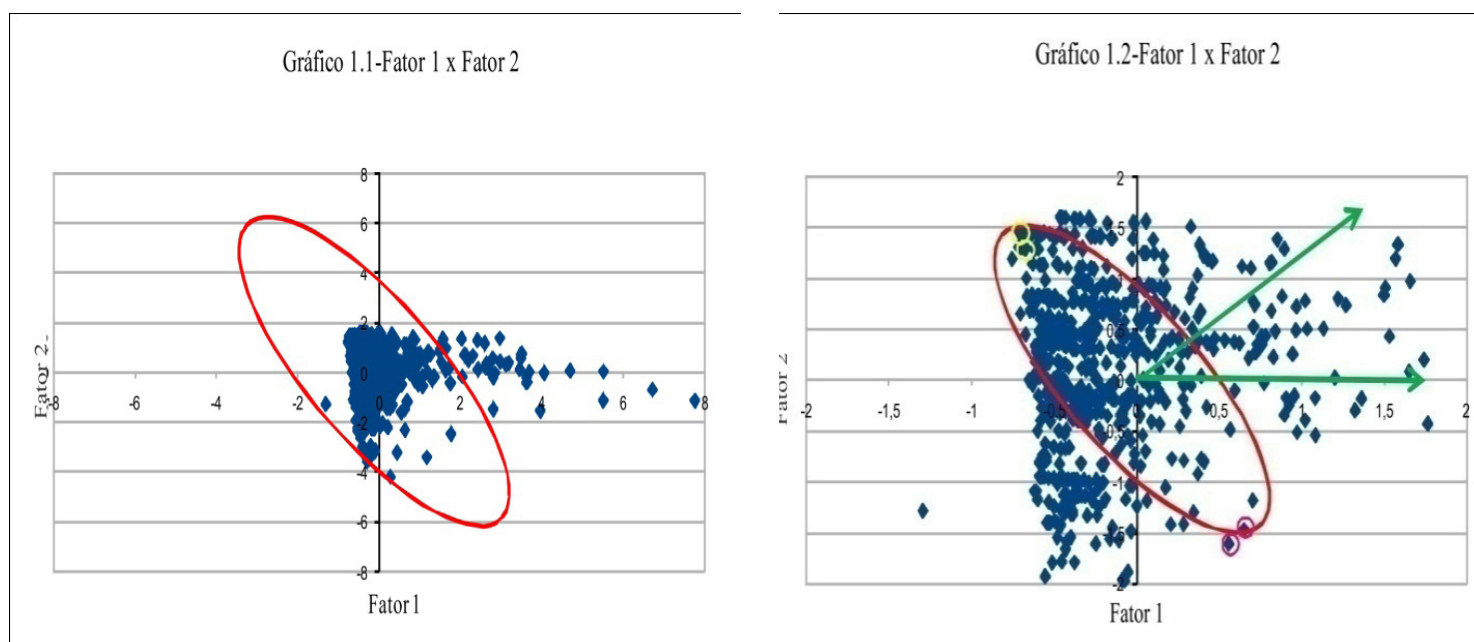

Gráfico 1: Distribuição das cooperativas de acordo com a sua carga fatorial,

Legenda: para o fator 1 - tamanho socioeconômico - e fator 2 - governança de forma tradicional. No gráfico 1.1, tem-se a vista da distribuição concentrada, em menor escala, com os outliners e no gráfico 1.2 tem-se a distribuição, em maior escala, sem outliners

Analisando-se duas cooperativas do cluster com as menores intensidades de cargas fatoriais de fator 1 e maiores intensidades de fator 2, situadas na extremidade superior no primeiro quadrante do Gráfico 1.2, representadas pelos círculos amarelos, é possível notar os seguintes resultados. 
A primeira cooperativa estudada com baixa carga fatorial do fator 1 apresenta os seguintes resultados: um pequeno número de associados com apenas 85 , receitas, despesas administrativas e sobras com valor zero, o ativo com total de $\mathrm{R} \$ 8.300$ e ausência de auditoria interna, mostrando que de fato tem uma baixa carga fatorial para o fator 1 que representa tamanho econômico e escala da cooperativa.

Essa mesma cooperativa apresenta uma das mais elevadas cargas fatoriais para o fator 2, atendendo aos requisitos de : presença de educação cooperativa, existência de comitê eleitoral, realização de treinamento para os conselheiros fiscais, prestação de contas dos diretores para o Conselho de Administração e o diretor-presidente da cooperativa é o mesmo presidente do Conselho de Administração.

A segunda cooperativa analisada desse cluster também apresenta uma baixa carga fatorial do fator 1 e uma das mais elevadas cargas fatoriais do fator 2, apresentando resultados semelhantes à análise anterior. Para o fator 1, o número de associados é 382, apresentando receita, sobras, despesas administrativas com valor igual a zero e a não existência de auditoria interna, e ativo no valor de $\mathrm{R} \$ 1.324 .651$, comprovando a baixa carga fatorial em relação a tamanho econômico e escala.

Em relação ao fator 2 referentes às práticas de cooperativas tradicionais sem a separação entre a propriedade e a gestão, os resultados mostram que a cooperativa realiza educação cooperativista, existe Comitê Eleitoral formalizado, os conselheiros fiscais recebem treinamento, os diretores prestam contas de suas atividades para o Conselho de Administração e o diretorpresidente da cooperativa também ocupa o cargo de diretor do Conselho de Administração, mostrando não haver separação entre propriedade e gestão.

Analisando agora duas cooperativas de outro cluster, com as maiores cargas do fator 1 e menores cargas de fator 2, localizadas na parte inferior e extrema do terceiro quadrante representadas pelos círculos em cor rosa, é possível notar os seguintes resultados.

A primeira cooperativa analisada apresenta número de associados de 3.948 , receita no valor de $\mathrm{R} \$ 4.660 .024$, valor de sobras de $\mathrm{R} \$ 1.460 .069$, despesas administrativas de $\mathrm{R} \$ 682.111$, ativo de R \$22.651.005 e não apresenta auditoria interna. Apesar de essa última característica ser parte do fator 1 de tamanho econômico e escala, essa cooperativa apresenta uma elevada carga fatorial, como é possível notar de acordo com os valores acima demonstrados.

Em relação ao fator 2 de práticas de cooperativas tradicionais sem a separação entre a propriedade e a gestão, os resultados que atendem a essas especificações são: realização de treinamento dos conselheiros fiscais, cargo de diretor-presidente e presidente do Conselho de Administração ser ocupado pela mesma pessoa. Entretanto ela não apresenta educação cooperativista, mas possui comitê eleitoral e prestação de contas por parte dos diretores para o Conselho de Administração. Isso explica o fato de essa cooperativa ter uma baixa carga do fator 2 e estar situada como um dos últimos pontos do cluster do terceiro quadrante do Gráfico 1.

Analisando-se a segunda cooperativa desse cluster, o número de associados é de 15.559, o valor da receita é de $\mathrm{R} \$ 731.108$, de sobras $\mathrm{R} \$ 71.011$, valores gastos com despesas administrativas são de $\mathrm{R} \$ 613.618$, ativo de $\mathrm{R} \$ 2.892 .652$ e não apresenta auditoria interna assim como a cooperativa anterior.

Em relação às práticas tradicionais das cooperativas sem separação entre propriedade $\mathrm{e}$ gestão, os resultados também são os mesmos da cooperativa anterior, não apresentando educação cooperativista, existência de comitê eleitoral e prestação de contas por parte dos diretores para o Conselho de Administração. Mas essa cooperativa possui treinamento dos conselheiros fiscais, 
cargo de diretor-presidente e presidente do Conselho de Administração ser ocupado pela mesma pessoa. Esses resultados vêm corroborar o fato de a cooperativa estar localizada na parte inferior do terceiro quadrante onde a carga fatorial de tamanho e a escala econômica são elevadas e as de práticas tradicionais das cooperativas são baixas.

Assim, por meio dessas análises, é possível confirmar a validade do modelo em que um menor nível de tamanho econômico e escala estão associados, com práticas de participação em cooperativas com governança tradicional sem separação entre a propriedade e a gestão.

Quando se analisa a interseção das cargas fatoriais do fator 1 - tamanho econômico e social da cooperativa - com o fator 3 de maior intensidade de correlação com as práticas indicadas de governança corporativa, pode-se perceber pelos resultados encontrados, que não há dependência entre tamanho econômico e escala e a presença de melhores práticas de governança corporativa. É possível notar isso em função da distribuição dispersa das cooperativas não formando clusters distintos no Gráfico 2.

Entretanto, os resultados esperados da intersecção do fator 1 com o fator 3 seriam que as cooperativas com maiores cargas fatoriais do fator 1- tamanho econômico- teriam maior carga fatorial do fator 3 - boas práticas de governança. Ou as menores cargas do fator 1 também teriam menores cargas de 3. Esses resultados indicariam que tamanho econômico impactam nas boas práticas de governança corporativa.

Mas só seria verdade se de fato houvesse concentração das cooperativas dentro da área da elipse vermelha do gráfico abaixo. Essa área em vermelho representa elevada carga de fator 1 e elevada carga de fator 3 ou uma baixa carga de fator 1 com uma baixa carga de fator 3.Ou seja, cooperativas grandes com adesão as boas práticas de governança, ou cooperativas pequenas sem adesão as boas práticas de governança.

Contudo não é o que os dados apontam. Os resultados mostram que não há uma correlação entre tamanho econômico e escala e práticas de governança. Isso poder ser visto no Gráfico 2.
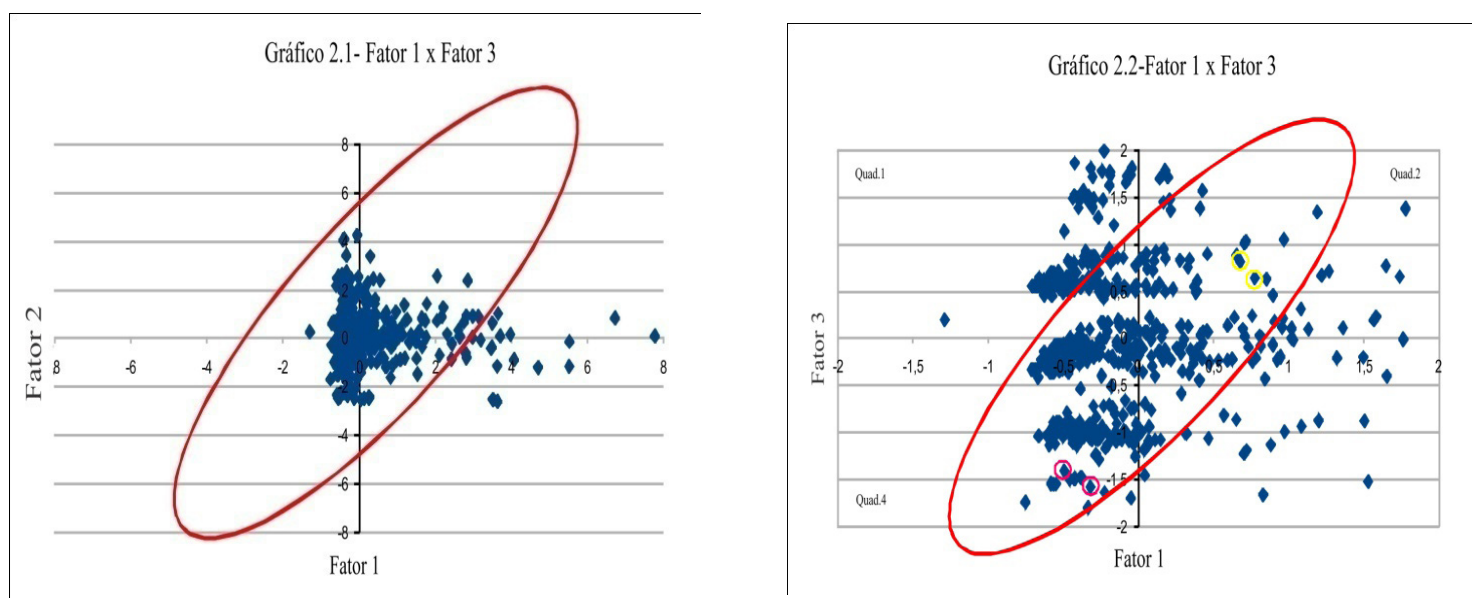

Gráfico 2: Distribuição das cooperativas de acordo com a sua carga fatorial,

Legenda: para o fator 1 - tamanho socioeconômico - e fator 3 - presença de práticas indicadas de governança. No gráfico 2.1, tem-se a vista da distribuição concentrada, em menor escala, com os outliners, no gráfico 2.2 tem-se a distribuição, em maior escala, sem outliners 
Analisando-se duas cooperativas com as maiores intensidades de cargas fatoriais do fator 1 e do fator 3, localizadas no cluster do segundo quadrante na parte superior do Gráfico 2, representadas por círculos na cor amarela, é possível notar os seguintes resultados.

A primeira cooperativa analisada apresenta número de associados de 1.815 , valor de receitas de $\mathrm{R} \$ 6.231 .528$, valor das sobras de $\mathrm{R} \$ 483.143$, gastos com despesas administrativas de $\mathrm{R} \$ 1.904 .851$, ativo de $\mathrm{R} \$ 31.772 .139$ e apresenta auditoria interna.

Em relação ao terceiro fator de práticas indicadas de governança corporativa para cooperativas, os resultados da cooperativa analisada são: permissão de inclusão prévia de pautas por parte dos associados nas assembleias, pré-requisitos para participação no Conselho Fiscal, chapas de Conselho de Administração e Conselho Fiscal independentes nas eleições, mostrando uma carga fatorial elevada para o fator 3. Entretanto, não há realização de assembleia por delegados, e o diretor-presidente também ocupa o cargo de conselheiro administrativo da organização.

Mesmo assim, esses resultados vêm corroborar o fato de a cooperativa estar localizada na parte superior do segundo quadrante do Gráfico 2, onde a carga fatorial de tamanho e escala econômica é elevada assim como a carga fatorial de práticas indicadas de governança.

Na segunda cooperativa analisada da intersecção do fator 1 com o fator 3 e suas maiores cargas fatoriais, é possível identificar os seguintes resultados: número de associados de 2.970, valor das receitas é $\mathrm{R} \$ 5.460 .902$, valor das sobras de $\mathrm{R} \$ 1.000 .831$, as despesas administrativas são de R\$1.923.218, ativo de R \$28.318.810 e possui auditoria interna.

Os resultados em relação às práticas de governança adotadas são as mesmas da cooperativa anterior, ou seja, permissão de inclusão prévia de pautas por parte dos associados nas assembleias, pré-requisitos para participação no Conselho Fiscal, chapas de Conselho de Administração e Conselho Fiscal independentes nas eleições, não há realização de assembleia por delegados e o diretor-presidente também ocupa o cargo de conselheiro administrativo da organização.

Agora, analisando duas cooperativas do quadrante 4, com as menores intensidades de cargas fatoriais do fator $1 \mathrm{com}$ a menor carga do fator 3, representadas pelos círculos em cor rosa, é possível notar os seguintes resultados.

A primeira delas tem como valores do fator 1 relativo ao tamanho econômico e à escala os seguintes dados: número de cooperados de 109 , valor das receitas de $\mathrm{R} \$ 210.073$, valor das sobras de $\mathrm{R} \$ 4.613$, gastos com despesas de $\mathrm{R} \$ 111.634$, valor do ativo de $\mathrm{R} \$ 886.351$ e não possui auditoria interna. É possível notar que devido a baixos valores que essa cooperativa se localiza no extremo inferior do quarto quadrante, ou seja, com uma baixa carga fatorial do fator 1 e fator 3 .

Em relação ao fator de práticas de governança corporativa indicadas, a cooperativa apresenta apenas a exigência de pré-requisitos para ser conselheiro fiscal. As demais práticas ela não possui, o que explica o fato de a cooperativa apresentar uma baixa carga fatorial para esse fator, localizando-se na parte extrema inferior do cluster do quarto quadrante do Gráfico 2.

A segunda cooperativa estudada dessa análise possui 512 cooperados, valor de receita de $\mathrm{R} \$ 1.697 .599$, valor de sobras de $\mathrm{R} \$ 220.756$, despesas administrativas de $\mathrm{R} \$ 891.468$ e não possui auditoria interna, sendo resultados semelhantes aos da cooperativa anterior.

Em relação a práticas de governança indicadas, os resultados também são iguais, apresentando apenas exigência de pré-requisitos para ser conselheiro fiscal. Esses resultados 
confirmam os dados encontrados na análise fatorial realizada no estudo.

Os resultados dessas análises mostram que não há dependência entre tamanho econômico e escala e a presença de melhores práticas de governança corporativa. Concomitantemente foi possível concluir que as práticas tradicionais de governança estão mais associadas às cooperativas com menor tamanho econômico.

Por fim, pode-se afirmar que há dois conjuntos de cooperativas. Aquelas que reúnem várias práticas indicadas de governança corporativa de forma correlacionada, e aquelas de gestão tradicional onde se têm correlacionadas às práticas correntes de governança característica das organizações cooperativas tradicionais.

Assim, esses resultados corroboram a questão de que não há dependência entre tamanho econômico e escala e a presença de melhores práticas de governança corporativa.

\subsection{Análise qualitativa da amostra}

Em uma análise total de 1195 cooperativas do estudo, 29,62\% possuem diretorpresidente contratado. O restante, $70,38 \%$ possui diretor-presidente eleito. Em um total de 998 cooperativas $94,28 \%$ tem o diretor-presidente como presidente em simultaneidade do Conselho de Administração.

Fazendo-se uma análise qualitativa dos dados encontrados nos quartis encontraram-se os seguintes resultados. O primeiro quartil representa as $25 \%$ maiores cooperativas em valores do ativo. Em relação à questão da administração da cooperativa ser feita por diretor contratado (executivo), $38 \%$ das cooperativas contratam seu diretor-presidente, enquanto $62 \%$ o elegem para o cargo.

Ainda no primeiro quartil com total de 283 cooperativas, 97,52\% possuem diretorpresidente como presidente do Conselho de Administração.

Em relação ao segundo e terceiro quartis sobre a questão de diretor-presidente ser eleito ou contratado, o total de cooperativas analisadas foi de 593, sendo assim, 27,84\% contratam seus diretores e $72,16 \%$ o elegem. Sobre a questão de o presidente-diretor também ser presidente do Conselho de Administração, o total de cooperativas analisadas é de 496, e em 93,34\% das organizações o cargo é ocupado pela mesma pessoa.

O último quartil, que representa os $25 \%$ menores ativos das cooperativas, tem como total de cooperativas analisadas para a questão de contratação ou eleição de diretor-presidente o número de 302 cooperativas, onde $24,5 \%$ contratam diretor-presidente e $75,5 \%$ fazem eleição. $\mathrm{Na}$ questão do diretor-presidente ser o presidente do Conselho Administrativo o total de cooperativas analisadas é de 215 , sendo que $91,16 \%$ tem o cargo ocupado pela mesma pessoa.

É possível notar que no quartil superior uma parcela das cooperativas que apresentam maiores ativos apresentam diretor-presidente contratado $(29,62 \%)$ e não há separação entre propriedade e gestão sendo o diretor-presidente da cooperativa o mesmo presidente do Conselho de Administração (94,28\%). Confirmando o resultado encontrado na pesquisa de que nível de tamanho econômico e escala não está associado com práticas de separação entre a propriedade e a gestão, característica das cooperativas tradicionais.

Se se pode pressupor que o tamanho de uma cooperativa é resultado de seu processo de crescimento, e esse processo econômico ocorre em função de sua eficiência, pode-se perguntar 
se a eficiência é correlacionada com o tamanho, essa não é correlacionada possivelmente com o tipo de governança.

Como já citado por Hilmmelberg et al (1999) os custos de agência e monitoramento tenderiam ser maiores nas grandes empresas, em função dos custos de monitoramento e das assimetrias de informação. Mas, não é isso que acontece com as cooperativas de crédito, como mostram os dados do gráfico 2 e das discussões qualitativas da amostra, pois não há relação percebível entre escala e tamanho econômico e a separação entre propriedade e gestão.

Assim formas tradicionais de governança coexistem com outras formas sem que o resultado ou as sobras ou número de associados ou despesas administrativas ou ativo sejam determinantes para isso. Assim há grandes cooperativas sendo gerenciadas de forma tradicional sem a divisão entre propriedade e gestão e outras já com um nível mais avançado de governança e de profissionalização. Como essas práticas também implicam em custos de governança, como a profissionalização e o monitoramento, entre outros, não há evidencias que as menores cooperativas não as tenham, implicando que novas análises deverão ser efetuadas.

O fato de que o conjunto das melhores práticas de governança corporativa não estarem correlacionados de forma significativa com o fator que representa escala e maior tamanho econômico, para as cooperativas de crédito, implica em uma nova questão para pesquisa, pois não se pode afirmar que há uma correlação diretamente proporcional como se esperava inicialmente.

Klapper e Love (2002) indicam que há influência da governança corporativa de duas formas opostas. As empresas maiores podem apresentar maiores problemas de agência decorrentes de seu fluxo de caixa livre, levando a uma necessidade de melhores práticas de governança para compensar esse problema. Além disso, as empresas maiores em geral dispõe de mais recursos para implementar práticas recomendadas de governança.

Já as cooperativas menores teriam em novas práticas de governança e de profissionalização e monitoramento um problema de custos.

\section{CONCLUSÕES}

É possível concluir, analisando-se a questão da separação entre a propriedade e a gestão, que essa variável se correlaciona negativamente com as variáveis de governança características de gestão tradicional. Ou seja, as cooperativas que apresentam cargos de diretor-presidente, e presidente do Conselho de Administração ocupado pela mesma pessoa apresentam também maior correlação de educação cooperativa, existência de comitê eleitoral, necessidade dos conselheiros fiscais receberem treinamento e a necessidade de que os diretores prestem contas de suas atividades. Para aferir a separação entre propriedade e gestão escolheu-se a variável que apresenta se o cargo de presidente da Cooperativa e do Conselho de Administração é ocupado pela mesma pessoa.

Entretanto essa mesma variável de separação entre propriedade e gestão se comporta de forma positiva com as outras variáveis que representam as melhores práticas de governança. Ou seja, as cooperativas que possuem cargo de diretor-presidente e presidente do Conselho de Administração ocupado por pessoas diferentes apresentam possibilidade de inclusão de pautas pelos associados em Assembleias Gerais, para ser eleito para o Conselho Fiscal são necessários pré-requisitos na área, as chapas de Conselho Fiscal e Conselho de Administração 
são independentes e as Assembleias Gerais Ordinárias acontecem em regime de delegados.

Para identificar o conjunto de práticas de governança corporativa, foram escolhidas as perguntas que indicassem o monitoramento, como a de presença de auditoria interna, a obrigatoriedade dos diretores em prestar contas, as que demonstram a preocupação com a especialização do Conselho Fiscal, e independência na eleição do Conselho de Administração e o Conselho Fiscal. Quanto às práticas de governança que representam a relação entre cooperados e a cooperativa, foram escolhidas variáveis como a presença de educação cooperativa, e as formas de realização da assembleia geral por delegação.

Por fim, essa mesma variável de separação entre a propriedade e a gestão não apresenta correlação com tamanho econômico e financeiro da cooperativa, mostrando que não há relação entre elas e as práticas indicadas pelo BACEN de governança corporativa. Tanto cooperativas grandes ou pequenas podem ou não ter essas práticas. Para essa análise foram escolhidas as variáveis que pudessem mostrar o tamanho social da cooperativa como número de cooperado, também aquelas que pudesse mostrar o tamanho financeiro da cooperativa como receitas, despesas administrativas, sobras e ativo.

Mas, pode-se afirmar que há dois conjuntos de cooperativas, aquelas que reúnem várias práticas indicadas de governança corporativa de forma correlacionada, e aquelas de gestão tradicional onde se tem correlacionadas as práticas correntes de governança características das organizações cooperativas tradicionais. Mas nenhum dos dois grupos esta associado com tamanho social e/ou econômico, ou ainda parâmetros de eficiência como os resultados ou a presença de sobras.

Essa análise implica em uma nova questão de pesquisa, se a divisão entre propriedade e gestão é importante para a eficiência dos negócios das cooperativas de crédito brasileiras ou se essas apresentam como organizações sociais uma diferente lógica de governança corporativa, que também pode ser eficiente.

\section{REFERÊNCIAS}

ALCHIAN, A. A.; DEMSETZ, H. Production, InformationCosts, andEconomicOrganization. The American EconomicReview, v.62, no.5, p. 777-795, 1972.

BANCO CENTRAL DO BRASIL. Disponível em $<$ http://www.bcb.gov.br $>$ Acesso em 12 de jan. 2012.

BAYSINGER, B. e HOSKISSON, R. E. The Composition of Boards of Directors and Strategic Control: Effects on Corporate Strategy. The Academy of Management Review, v. 15, n. 1, p. 72-87, Jan., 1990.

BECHT, M;BOLTON, P; ROELL, A. Corporate GovernanceandControl. ECGI WorkingPaper Series. WorkingPaper No. 02/2002. Updated August 2005.

BERLE, A. A.; MEANS, G. C. A moderna sociedade anônima e a propriedade privada. Tradução Dinah de Abreu Azevedo. São Paulo: Nova Cultural, 1987. 335p

COASE, R. H. The NatureoftheFirm. Economica, New Series, v. 4, no. 16, p. 386-405, 1937.

BIALOSKORSKI NETO, S.; BARROSO, M.F.G.; REZENDE, A. J. 
Cooperativegovernanceand management systems: agency costs theoretical approach. $\mathrm{V}$ Anpcont, 5. 2010. Anais... São Paulo, p.17.

BIALOSKORSKI NETO, S. DAVIS, P. Governança e gestão de capital social em cooperativas: uma abordagem baseada em valores. ESAC Economia Solidária e Ação Cooperativa. v. 5, n.1, 2010.

BIALOSKORSKI NETO, S. Um ensaio sobre desempenho econômico e participação em cooperativas agropecuárias. Revista de Economia e Sociologia Rural, v.45, n.1, p. 119-138, 2005.

COLE, C. R.; HE, E.; MCCULLOUGH, K. A.; SOMMER, D. W. Separation of ownership and management: implications for risk-taking behavior. Risk Management and Insurance Review. v.14, n. 1, p 49-71, 2011.

COSTA, D. R. M. Propriedade e decisões de gestão em organizações cooperativas agropecuárias brasileiras. 2010. 133 f. Tese (Doutorado em Economia de Organizações) Escola de Economia de São Paulo, Fundação Getúlio Vargas, São Paulo, 2010.

COSTA, D. R.M.; CHADDAD, F.R.; AZEVEDO, P.F. Separação entre propriedade e decisão de gestão nas cooperativas agropecuárias brasileiras. RESR, Piracicaba, v. 50, n. 2, p. 285300, 2012.

FAMA, E. F,; JENSEN, M. C. Separation of Ownership and Control. Journal of Law and Economics.V.. 26, $n^{\circ}$. 2, p. 301-325, 1983.

HANSMANN, H.The Ownership of Enterprise, Belknap Press of Harvard University Press, 1996.

HART, O. MOORE, J. Cooperatives vs. OutsideOwnership. NBER WORKING PAPER SERIES. WorkingPaper No. 6421, 1998.

HILMMERLBERG, C.; HUBBARD, G.; PALIA, D. Understanding the determinants of managerial ownership and the link between ownership and performance. Journal of Financial Economics, v. 53, p.353-384, 1999.

INSTITUTO BRASLEIRO DE GOVERNANÇA CORPORATIVA - IBGC. Código das Melhores Práticas de Governança Corporativa. 4.ed. São Paulo, SP, 2009, 73 p. Disponível em: <http://www.ibgc.org.br/CodigoMelhoresPraticas.aspx> . Acesso em: 07 Set. 2011.

INSTITUTO BRASLEIRO DE GOVERNANÇA CORPORATIVA - IBGC. Disponível em: < http://www.ibgc.org.br >. Acesso em: 02 dez. 2012.

JENSEN, M C.; MECKLING, W. H. TheoryoftheFirm: managerialbehavior, agencycostsandownershipstructure. Journalof Financial Economics, v. 3, n. 4, p. 305-360, out. 1976.

KLAPPER, L; LOVE, I. Corporate governance, investorprotection, andperformance in emergingmarkets. World Bank Policyresearch, workingpaper n. 2818, Updatedabril, 2002.

MCGRAW, T. K.; CHANDLER, A. Ensaios para uma teoria histórica da grande empresa. Rio de Janeiro: FGV, 1998.

PELLERVO, CONFEDERATION OF FINNISH COOPERATIVES. Corporate Governance and Management Control in Cooperative. Nov., 2000. Disponível em: $<$ http://www.pellervo. 
fi/cg/raportti.pdf> Acesso em: 6 de dez. 2012.

PINHEIRO, M. A. H. Cooperativas de crédito: história da evolução normativa no Brasil. $6^{\text {a }}$ edição. Brasília: Banco Central, 2008.

PINTO, G. M.S.; FUNCHAL, B.; COSTA, F. M. da.Governança corporativa e o desempenho das cooperativas de crédito do Brasil. III Anpcont, 3.2009. São Paulo. Anais... São Paulo, p.17.

SAMPIERI, R. H.; COLLADO, C. F.; LUCIO, P. B. Metodologia de Pesquisa. $3^{\text {a }}$. Edição. São Paulo: McGrawHill, 2006. 584p.

SHLEIFER, A., VISHNY, R. A surveyofcorporategovernance, The JournalofFinance, Oxford, v. 52, n. 2, p. 737-783, jun. 1997.

SILVEIRA, A. D. M. da.Governança corporativa e estrutura de propriedade: determinantes e relação com o desempenho das empresas no Brasil. 2004. 245f. Tese de doutorado. Faculdade de Economia Administração e Contabilidade, USP. São Paulo.

TRINDADE, M. T.;FERREIRA FILHO, F.de A.; BIALOSKORSKI NETO, S. Brazilian credit co-operatives and financial Banks: a ten years performance comparison. Journal of Cooperative Studies, v.43, n.1, p14-29, Apr. 2010.

VENTURA, E. C. F.(Coord.). Governança cooperativa: diretrizes e mecanismos para fortalecimento da governança em cooperativas de crédito - Brasília, DF: BCB, 2009.

WILLIAMSON, O. E. The economic institutions of capitalism. Freepress ,1985.

.The mechanisms of governance. Oxford University Press, 1996.

ZYLBERSZTAIN, D. Estruturas de governança e coordenação do agribusiness: Uma aplicação da nova economia das instituições. São Paulo, FEA/USP, Tese de livre docência. $1995,238 p$ 


\section{DADOS DOS AUTORES:}

\section{LUANA ZANETTI TRINDADE}

Universidade de São Paulo.

Av. dos Bandeirantes, 3900

Cidade Universitária

14040-900 - Ribeirão Preto, SP - Brasil

\section{SIGISMUNDO BIALOSKORSKI NETO}

Universidade de São Paulo.

Av. dos Bandeirantes, 3900

Cidade Universitária

14040-900 - Ribeirão Preto, SP - Brasil 